\title{
Solid dispersions in the form of electrospun core-sheath nanofibers
}

\author{
This article was published in the following Dove Press journal: \\ International Journal of Nanomedicine \\ 9 December 2011 \\ Number of times this article has been viewed
}

\section{Deng-Guang $\mathrm{Yu}^{\prime}$ \\ Li-Min Zhu ${ }^{2}$ \\ Christopher J \\ Branford-White ${ }^{3}$ \\ Jun-He Yang' \\ Xia Wang' \\ Ying $\mathrm{Li}^{\prime}$ \\ Wei Qian'}

'School of Materials Science and Engineering, University of Shanghai for Science and Technology; ${ }^{2}$ College of Chemistry, Chemical Engineering and Biotechnology, Donghua University, Shanghai, People's Republic of China;

${ }^{3}$ Faculty of Life Sciences, London

Metropolitan University, London, United Kingdom
Correspondence: Deng-Guang Yu; Xia Wang

School of Materials Science and Engineering, University of Shanghai for Science and Technology, 516 Jungong Road,Yangpu District, Shanghai 200093,

People's Republic of China

Tel +86 2I 55274069

Fax +86 2I 55270632

Emailydg0I7@gmail.com;

wangxia@usst.edu.cn
Background: The objective of this investigation was to develop a new type of solid dispersion in the form of core-sheath nanofibers using coaxial electrospinning for poorly water-soluble drugs. Different functional ingredients can be placed in various parts of core-sheath nanofibers to improve synergistically the dissolution and permeation properties of encapsulated drugs and to enable drugs to exert their actions.

Methods: Using acyclovir as a model drug, polyvinylpyrrolidone as the hydrophilic filamentforming polymer matrix, sodium dodecyl sulfate as a transmembrane enhancer, and sucralose as a sweetener, core-sheath nanofibers were successfully prepared, with the sheath part consisting of polyvinylpyrrolidone, sodium dodecyl sulfate, and sucralose, and the core part composed of polyvinylpyrrolidone and acyclovir.

Results: The core-sheath nanofibers had an average diameter of $410 \pm 94 \mathrm{~nm}$ with a uniform structure and smooth surface. Differential scanning calorimetry and x-ray diffraction results demonstrated that acyclovir, sodium dodecyl sulfate, and sucralose were well distributed in the polyvinylpyrrolidone matrix in an amorphous state due to favoring of second-order interactions. In vitro dissolution and permeation studies showed that the core-sheath nanofiber solid dispersions could rapidly release acyclovir within one minute, with an over six-fold increased permeation rate across the sublingual mucosa compared with that of crude acyclovir particles.

Conclusion: The study reported here provides an example of the systematic design, preparation, characterization, and application of a novel type of solid dispersion consisting of multiple components and structural characteristics.

Keywords: core-sheath nanofibers, solid dispersion, coaxial electrospinning, poorly water-soluble drug, dissolution, permeation

\section{Introduction}

Nanomedicine is a new field and an offshoot of nanotechnology, which focuses on the new properties of medical materials gained when structures are controlled at the atomic and molecular levels, leading to significantly changed properties distinct from traditional science fields. ${ }^{1}$ Nano drug delivery systems, as a subset of nanomedicine, have shown great potential in meeting many difficult pharmaceutical challenges, such as effective absorption of poorly water-soluble drugs, targeting cancer, oral vaccine and protein delivery, gene therapy, combating multidrug resistance, and trans blood-brain barrier drug delivery systems., ${ }^{2,3}$

Electrospinning is a simple and straightforward process for generating nanofibers. The popularity of this system is due to its ease of implementation, capability of being used with a variety of materials, convenience in obtaining composites of multiple 
components, and with secondary microstructures (such as core-sheath, side-by-side, and island-in-sea). The applications of electrospun products are expanding, especially in areas relating to tissue engineering and drug delivery. ${ }^{4-8}$

Solid dispersion is one of the more promising strategies to improve the oral bioavailability of poorly water-soluble drugs, and is mainly obtained by two traditional methods, ie, melting and solvent evaporation. ${ }^{9-14}$ Over several decades, research concerning the development of solid dispersions and related fabrication processes has been widely reported, and a few solid dispersion products have already been marketed. Recently, it has been shown that the dissolution profile can be enhanced if the carrier has surface activity or self-emulsifying properties. Therefore, third-generation solid dispersions have been developed, usually consisting of an active pharmaceutical ingredient, an amorphous polymer, and a surfactant. The objective of this new generation of solid dispersions is to achieve a higher degree of bioavailability for poorly soluble drugs that stabilize the solid dispersion, so avoiding drug recrystallization. ${ }^{15-17}$ However, all the reported solid dispersions, as intermediate formulations, are complexes or amorphous hybrids of two or multiple components and often lack secondary microstructural characteristics. If solid dispersions are designed with secondary structures, then this approach may not only provide greater physical stability, so avoiding recrystallization, but may also have new properties because of tactical deposition of varying functional ingredients in different locations within the solid dispersion.

Electrospinning, which has the shared characteristics of both electrospraying and conventional solution dry spinning of fibers, is inherently an appropriate method for preparing solid dispersions. ${ }^{18-20}$ Correspondingly, electrospun nanofibers can be good solid dispersion products. The fast-drying electrospinning process is able to "freeze" drug molecules randomly in the solid polymer fiber matrix into a state comparable with that in a liquid form. This is very useful for preventing phase separation, eg, recrystallization of either drug or matrix during removal of solvents. ${ }^{15-20}$ Exploitation of electrospinning in preparing solid dispersions is at present still somewhat limited, in that all the reported solid dispersions are produced by single fluid electrospinning and the nanofiberbased solid dispersions formed invariably do not have structural characteristics. ${ }^{16-20}$ Over the past few years, electrospinning technology has evolved from using single, coaxial, and sideby-side electrospinning, to adopting multiple fluid systems. These techniques allow the formation of new types of sophisticated nanofibers with well defined microstructures, novel morphologies, and/or new functions. ${ }^{21-25}$
Among all the different types of electrospinning processes, coaxial electrospinning, in which a concentric spinneret can accommodate two different liquids, is regarded as one of the most significant breakthroughs in the field. ${ }^{26-28}$ It has been applied in controlling secondary structures of nanofibers, encapsulating drugs or biological agents into polymeric nanofibers, fabricating polymeric microtubes, preparing nanofibers from materials that lack filamentforming properties, and enclosing functional liquids within the fiber matrix. ${ }^{29-33}$ Through modifications, nanofiber diameters can be manipulated for controlling the size of self-assembled nanoparticles, preparing ultrafine structures from concentrated polymer solutions, and improving nanofiber quality systematically. ${ }^{34-39}$

Based on the above knowledge, we report on the formation of a novel solid dispersion in the form of coresheath nanofibers produced using a coaxial electrospinning process. We believe that this is the first investigation of nano solid dispersions consisting of multiple components, with each constituent having its own spatial deposition in the nanofibers and the resulting format influencing functional characteristics.

\section{Materials and methods Materials}

Polyvinylpyrrolidone (PVP) K60 (molecular weight 360,000) was purchased from BASF Corporation (Shanghai, China), acyclovir from Zhejiang Charioteer Pharmaceutical Company (Hangzhou, China), and sucralose and sodium dodecyl sulfate (SDS) from Sinopharm Chemical Reagent Co, Ltd (Shanghai, China). N,N-dimethylacetamide (DMAc) and anhydrous ethanol were provided by Shanghai Shiyi Chemicals Reagent Co, Ltd (Shanghai, China). All chemicals used were analytical grade. Water was double-distilled just before use.

\section{Coaxial electrospinning process}

A codissolving solution of 10\% (w/v) PVP and 2\% (w/v) acyclovir in a mixed solvent of DMAc:ethanol (4:6, v:v) was used as a core fluid. The electrospinnable sheath liquid consisted of $10 \%(\mathrm{w} / \mathrm{v})$ PVP, $0.5 \%(\mathrm{w} / \mathrm{v}) \mathrm{SDS}$, and $0.2 \%(\mathrm{w} / \mathrm{v})$ sucralose in a mixed solvent of water:ethanol $(2: 8, \mathrm{v}: \mathrm{v})$.

A concentric spinneret with a coplanar inner and outer capillary was used to carry out the coaxial electrospinning. ${ }^{36}$ Two syringe pumps (KDS100 and KDS200, Cole-Parmer, Vernon Hills, IL) were used to drive the sheath and core fluids at the same flow rate of $1.0 \mathrm{~mL} /$ hour. A metal clip was used to connect the spinneret with the high voltage supply (Shanghai Sute Electrical Co, Ltd, Shanghai, China) and the 
applied voltage was $12 \mathrm{kV}$. The nanofibers were collected on a metal collector wrapped with aluminum foil and kept at a fixed distance of $20 \mathrm{~cm}$ away from the needle tip of the spinneret. The coaxial processes were recorded using a digital video recorder (PowerShot A640, Canon, Japan) under magnification of $11 \times$.

\section{Characterization}

The morphology of the surface and cross-sections of the core-sheath nanofibers were assessed using a S-4800 fieldemission scanning electron microscope (FESEM, Hitachi, Japan). The average fiber diameter was determined by measuring diameters of nanofibers over 100 points from the FESEM images using Image J software (National Institutes of Health, Bethesda, MD). Before carbon-coating, crosssections of the nanofiber mats were prepared by placing them into liquid nitrogen for over 15 minutes before manual breaking.

Transmission electron microscopy images of the samples were taken on a JEM 2100F FESEM (JEOL, Tokyo, Japan). Transmission electron microscopy samples of core-sheath nanofibers were prepared by fixing a lacey carbon-coated copper grid on the metal collector. Nanofibers were spun directly onto the grid.

\section{Physical status of components and their interactions}

Differential scanning calorimetry (DSC) analyses were carried out using an MDSC 2910 differential scanning calorimeter (TA Instruments Co, New Castle, DE). Sealed samples were heated at $10^{\circ} \mathrm{C}$ per minute from ambient temperature $\left(21^{\circ} \mathrm{C}\right)$ to $300^{\circ} \mathrm{C}$. The nitrogen gas flow rate was $40 \mathrm{~mL} / \mathrm{minute}$.

$\mathrm{X}$-ray diffraction analysis were obtained on a D/Max-BR diffractometer (RigaKu, Japan) with $\mathrm{Cu} \mathrm{K} \alpha$ radiation in the $2 \theta$ range of $5^{\circ}-60^{\circ}$ at $40 \mathrm{mV}$ and $300 \mathrm{~mA}$.

Attenuated total reflectance Fourier transform infrared (ATR-FTIR) analysis was carried out on a Nicolet-Nexus 670 FTIR spectrometer (Nicolet Instrument Corporation, Madison, WI) over the range $500-4000 \mathrm{~cm}^{-1}$ and a resolution of $2 \mathrm{~cm}^{-1}$.

\section{In vitro dissolution and permeation tests}

The in vitro dissolution studies were carried out according to the Chinese Pharmacopeia (2005 ED) Method II, and a paddle method using a RCZ-8A dissolution apparatus (Tianjin University Radio Factory, China) was carried out. Core-sheath nanofibers $(227 \mathrm{mg}$ ) or $20 \mathrm{mg}$ of crude acyclovir particles $(<100 \mu \mathrm{m})$ were placed in $600 \mathrm{~mL}$ of phosphatebuffered solution ( $\mathrm{pH} 6.8,0.1 \mathrm{M}$ ) at $37^{\circ} \mathrm{C} \pm 1^{\circ} \mathrm{C}$ and $50 \mathrm{rpm}$, in sink conditions of $C<0.2 C_{\mathrm{s}}$. At predetermined time intervals, $5.0 \mathrm{~mL}$ samples were withdrawn and replaced with fresh medium to maintain a constant volume. After filtration through a $0.22 \mu \mathrm{m}$ membrane (Millipore, Bedford, MA) and appropriate dilution with phosphate-buffered solution, the sample solutions were analyzed at $252 \mathrm{~nm}$ using an ultraviolet spectrophotometer (Unico Instrument Co, Ltd, Shanghai, China). All measurements were carried out in triplicate.

\section{In vitro buccal permeation studies}

The in vitro permeation studies were performed using a RYJ-6A diffusion test apparatus (Shanghai Huanghai Drug Control Instrument Co, Ltd), in which material was mounted on six Keshary-Chien glass diffusion cells and a water bath system that maintained a constant temperature of $37^{\circ} \mathrm{C} \pm 0.2^{\circ} \mathrm{C}$. Each cell had a diffusion area of $2.60 \mathrm{~cm}^{2}$ and the receptor compartment had a capacity of $7.2 \mathrm{~mL}$.

Porcine sublingual mucosa obtained from a local abattoir was mounted between the donor and receptor compartments of the diffusion cells, with the mucosal surface uppermost. This was performed within 2 hours of slaughter. Each donor compartment was filled with $1 \mathrm{~mL}$ of phosphate-buffered solution, and the hydrodynamics in the receptor compartment were maintained by stirring with a Teflon-coated magnetic bead at $100 \mathrm{rpm}$. The sublingual membranes were equilibrated for 30 minutes before permeation tests.

Core-sheath nanofibers $(1.14 \mathrm{mg})$ or $0.1 \mathrm{mg}$ of crude acyclovir particles $(<100 \mu \mathrm{m})$ were placed on the mucosal surface. Samples $(1 \mathrm{~mL})$ were withdrawn from the receptor compartment at timed intervals, filtered through a $0.22 \mu \mathrm{m}$ membrane (Millipore) and absorption was measured at $252 \mathrm{~nm}$ as before. All measurements were carried out in triplicate.

\section{Results and discussion Coaxial electrospinning}

A schematic diagram of the coaxial electrospinning process and digital pictures of the process are shown in Figure 1. Coaxial electrospinning appeared to proceed smoothly under the conditions used. Acyclovir, a poorly water-soluble drug, has a high melting point $\left(257^{\circ} \mathrm{C}\right)$ and also has poor solubility in a series of typical organic solvents, such as ethanol, methanol, chloroform, and acetone. There are no previous reports of the use of this drug in solid dispersions using traditional melt and solvent evaporation methods. Although acyclovir is soluble in DMAc, PVP cannot be electrospun 

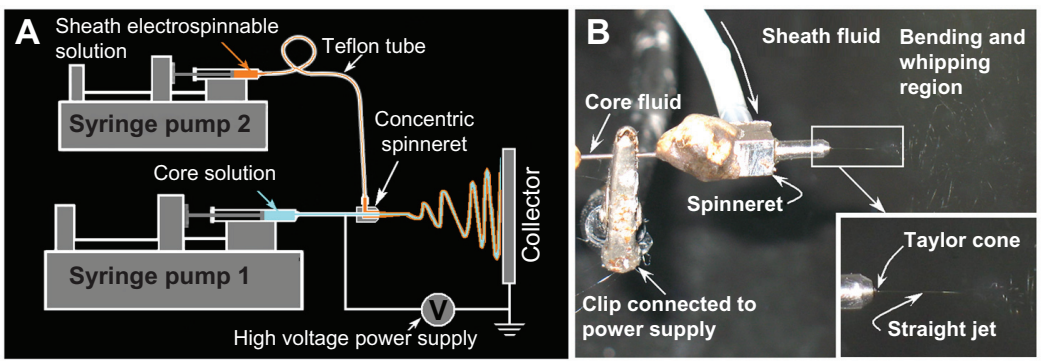

Figure I Schematic diagram of the coaxial electrospinning process $(\mathbf{A})$ and digital pictures of the process (B).

under these conditions due to its high boiling point $\left(166^{\circ} \mathrm{C}\right)$ and poor volatility, thus it is impossible to prepare nanofiber solid dispersions of multiple components using single fluid electrospinning. This is due to the lack of cosolubility of the components or good electrospinnability.

For coaxial electrospinning, the core solution does not need to have electrospinnability, and the sheath solution acts as a guide and surrounds the core liquid. The sheath solution is critical, and the sheath polymer-solvent system selected should be electrospinnable by itself to facilitate formation of a core-sheath structure in the nanofibers. ${ }^{40-42}$ Thus, although the core solution consisting of $10 \%(\mathrm{w} / \mathrm{v})$ PVP and $2 \%(\mathrm{w} / \mathrm{v})$ acyclovir in a mixed solvent of DMAc:ethanol (4:6, v:v) was nonelectrospinnable, the electrospinnable sheath fluid consisting of $10 \%(\mathrm{w} / \mathrm{v})$ PVP, $0.5 \%(\mathrm{w} / \mathrm{v})$ SDS, and $0.2 \%$ $(\mathrm{w} / \mathrm{v})$ sucralose in a mixed solvent of water:ethanol $(2: 8, \mathrm{v}: \mathrm{v})$ was able to ensure a smooth coaxial electrospinning process and formation of core-sheath nanofibers.
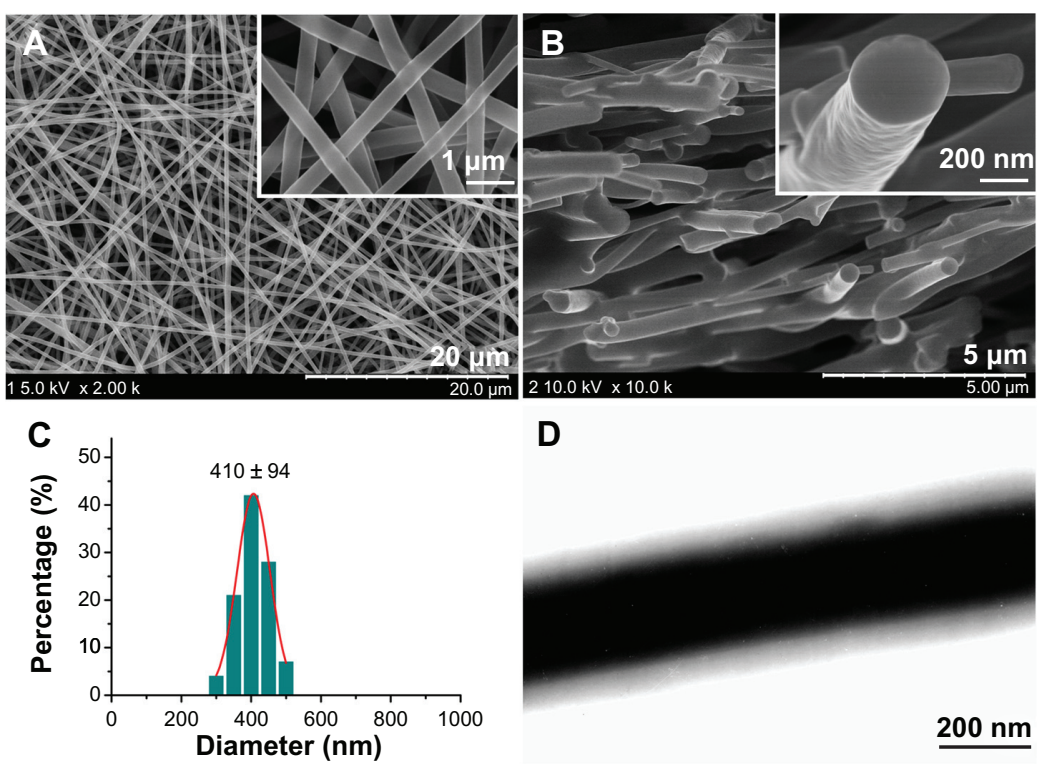

D

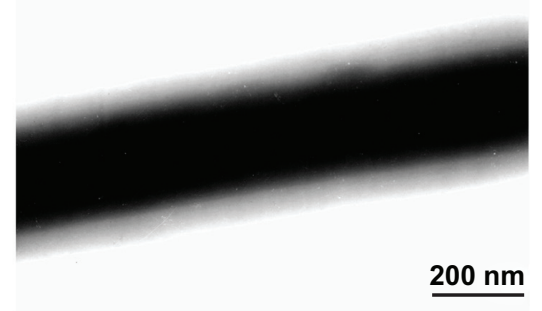

Figure 2 Characterization of the electrospun core-sheath nanofibers. (A) FESEM images of nanofiber surfaces; (B) FESEM images of nanofiber cross-sections; (C) distribution of nanofiber diameters; (D) TEM images of the fiber core-sheath structure.

Abbreviations: FESEM, field emission scanning electron microscope; TEM, transmission electron microscopy.

On the other hand, the critical voltage applied to a fluid to initiate Taylor cone formation and the straight thinning jet $\left(V_{c}\right)$ has a close relationship with the surface tension and conductivity of fluid: ${ }^{43}$

$$
V_{c} \sim \sqrt{\frac{\gamma d^{2}}{\varepsilon R}}
$$

where $V_{c}$ is the critical voltage for a jet emanating from the meniscus tip, $d$ is the electrode separation, $\varepsilon$ is the permittivity, $\gamma$ is the surface tension, and $R$ is the principal curvature of the liquid meniscus. The addition of SDS and sucralose to the sheath solution would reduce the surface tension and increase the permittivity of the sheath fluid, and thus in turn decrease the applied voltage value needed to initiate coaxial electrospinning.

\section{Morphology}

Figure 2A and B show FESEM images of the surface and cross-section of the core-sheath nanofiber mats. 
The nanofibers had a uniform structure without beads-on-astring morphology. They had smooth surfaces and the matrix was free of any separating particles. The nanofibers were evenly distributed, with an average diameter of $410 \pm 94 \mathrm{~nm}$ (Figure 2C).

Transmission electron microscopy images (Figure 2D) clearly demonstrate the core-sheath structure of the nanofibers, and the uniform gray shading of the sheath and core parts of the nanofibers indicate that acyclovir is evenly distributed in the PVP matrix in the core part and SDS and sucralose are distributed in the PVP matrix in the sheath region.

\section{Physical status of components in electrospun fibers}

DSC and x-ray diffraction tests were undertaken to determine the physical status of the components contained in the coresheath nanofibers. DSC thermograms are shown (Figure 3), and the DSC curves of pure acyclovir and sucralose show a single endothermic response corresponding to melting points of $257^{\circ} \mathrm{C}$ and $130^{\circ} \mathrm{C}$, respectively. SDS had a melting point of $182^{\circ} \mathrm{C}$ followed by a decomposing temperature of $213^{\circ} \mathrm{C}$. As an amorphous polymer, PVP K60 did not show any fusion peaks or phase transitions, apart from a broad endotherm, this being due to dehydration, and lying between $80^{\circ} \mathrm{C}$ and $120^{\circ} \mathrm{C}$, with a peak at $85^{\circ} \mathrm{C} .{ }^{44}$

DSC thermograms of nanofibers did not exhibit any melting peaks for small molecules. The nanofibers had a broad endotherm ranging from about $60^{\circ} \mathrm{C}$ to $100^{\circ} \mathrm{C}$ with a peak at $79^{\circ} \mathrm{C}$. However, the decomposition bands of SDS in the

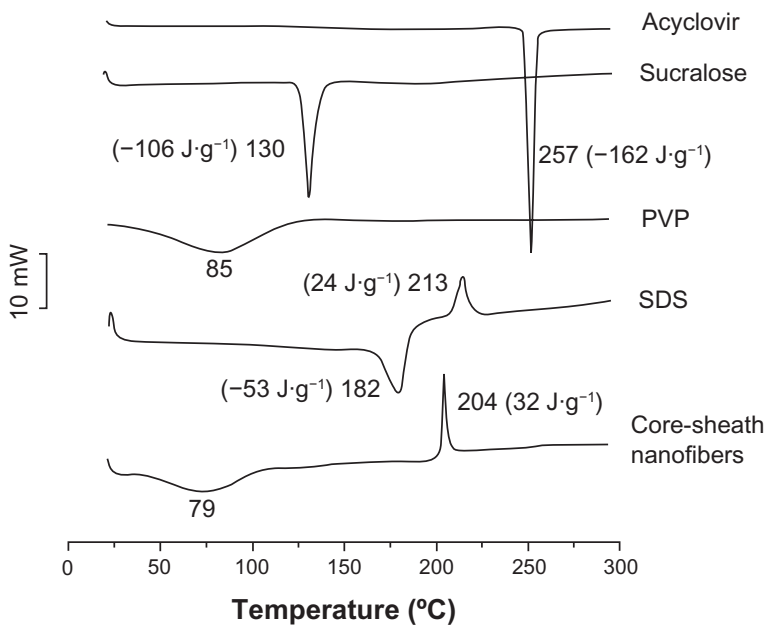

Figure 3 Differential scanning calorimetry thermograms of the components (acyclovir, PVP, SDS, and sucralose) and their core-sheath nanofibers under a heating rate of $10^{\circ} \mathrm{C}$ per minute and a nitrogen gas flow rate of $40 \mathrm{~mL} /$ minute. Abbreviations: PVP, polyvinylpyrrolidone; SDS, sodium dodecyl sulfate. core-sheath nanofibers were narrower and higher than that of pure SDS. The peak temperatures of decomposition shifted from $204^{\circ} \mathrm{C}$. These results suggest that acyclovir, SDS, and sucralose were no longer present as a crystalline material but that their respective parts had been converted into an amorphous state in the core-sheath nanofibers.

As shown in Figure 4, the presence of numerous distinct peaks in the $\mathrm{X}$-ray diffraction patterns indicated that acyclovir, sucralose, and SDS were present as crystalline materials with characteristic diffraction peaks. The PVP diffraction exhibited a diffuse background pattern with two diffraction halos, indicating that the polymer was amorphous. ${ }^{45}$ Similarly, the results of DSC and x-ray diffraction demonstrated that the small functional molecules (acyclovir, sucralose, and SDS) were widely distributed in the PVP matrix and were present in a complex manner whereby the original structure of the pure materials was lost.

\section{Secondary interactions among components}

Compatibility between components is essential for producing nanofibers of high quality and stability. Often the

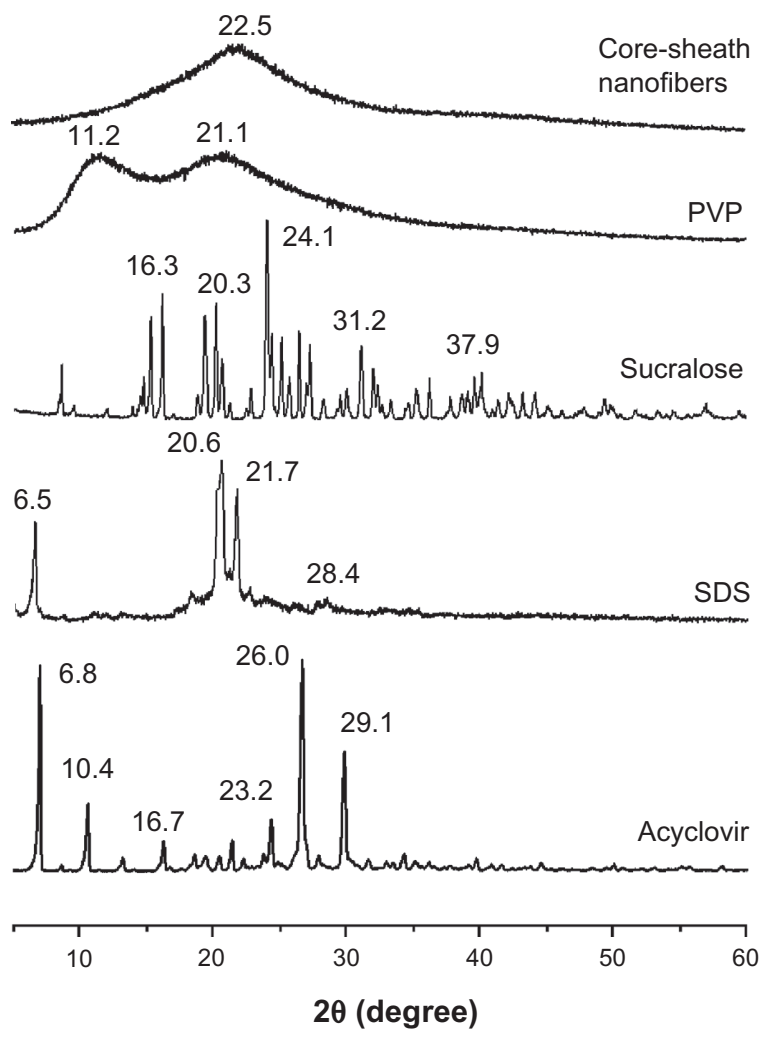

Figure 4 X-ray diffraction patterns of the components (acyclovir, PVP, SDS, and sucralose) and their core-sheath nanofibers with CuK $\alpha$ radiation at $40 \mathrm{mV}$ and $300 \mathrm{~mA}$.

Abbreviations: PVP, polyvinylpyrrolidone; SDS, sodium dodecyl sulfate. 
A

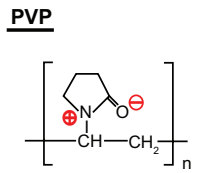

$\underline{\text { SDS }}$

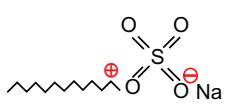

$\underline{A C Y}$

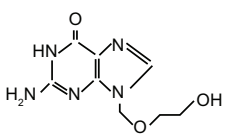

Sucralose

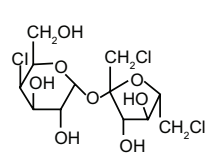

B
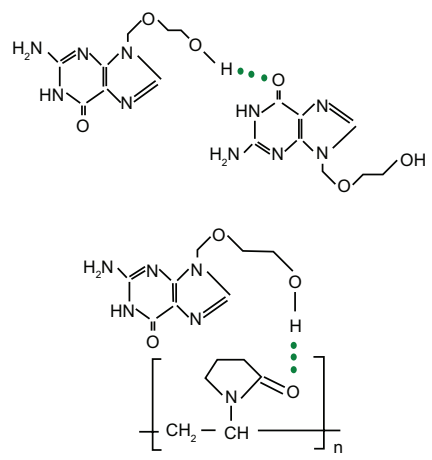

Figure 5 Molecular structures of the components $(\mathbf{A})$ and hydrogen bonding between acyclovir molecules and between acyclovir and PVP molecules (B). Abbreviation: PVP, polyvinylpyrrolidone.

second-order interactions, such as hydrogen bonding, electrostatic interactions, and hydrophobic interactions would improve compatibility. ${ }^{46}$ The molecular structures of the four components are shown (Figure 5A). Acyclovir and sucralose molecules contain free hydroxyl groups which could act as potential proton donors for hydrogen bonding. SDS has $\mathrm{S}=\mathrm{O}$ groups and PVP has carbonyl groups which could act as proton receptors. Therefore, it can be postulated that hydrogen bonding can occur within the core-sheath nanofibers through interactions determined by the specific presence of these groups.

Acyclovir molecules have both $-\mathrm{OH}$ groups and $-\mathrm{C}=\mathrm{O}$ groups, and so hydrogen bonds can form between the drug molecules (Figure 5B). This can be verified from the ATRFTIR spectra in which sharp peaks are visible for pure crystalline acyclovir at $1698 \mathrm{~cm}^{-1}$ and $1632 \mathrm{~cm}^{-1}$ (Figure 6), representing the stretching vibration of $-\mathrm{C}=\mathrm{O}$ groups for the different states. However, all the peaks for acyclovir were absent in the core-sheath nanofibers when samples were evaluated using ATR-FTIR spectra. Only one large peak at $1654 \mathrm{~cm}^{-1}$ can be identified for the core-sheath nanofibers. This result indicates that hydrogen bonding between the PVP carbonyl group and the oxhydryl group of the acyclovir molecule occurs (Figure 5B). In respect to acyclovir, by interacting with the polymer, the structure is less likely to form the dimers that are necessary for constructing a crystal lattice.

The disappearance of absorbance of $-\mathrm{C}=\mathrm{O}$ groups in acyclovir, the shift to a lower wavenumber of peaks assigned to the $\mathrm{C}=\mathrm{O}$ stretching vibrations in $\mathrm{PVP}$ (from $1663 \mathrm{~cm}^{-1}$ to $1654 \mathrm{~cm}^{-1}$ for the core-sheath nanofibers), and the disappearance of multiple peaks within the $3000-4000 \mathrm{~cm}^{-1}$ regions (related to the $\mathrm{O}-\mathrm{H}$ stretching vibrations in sucralose and acyclovir) together demonstrate that hydrogen bonding was occurring.
The absorption of SDS (C-H stretching) at $2917 \mathrm{~cm}^{-1}$ and $2850 \mathrm{~cm}^{-1}$ and PVP (C-H stretching) at $2954 \mathrm{~cm}^{-1}$ were not present in the core-sheath nanofibers when compared with single SDS and PVP. However, a broader and weaker band at $2917 \mathrm{~cm}^{-1}$ appeared, which is indicative of hydrophobic interactions between the PVP and SDS molecules. Although electrostatic interactions cannot be determined from the ATRFTIR spectra, they do exist between the negatively charged SDS head group and the nitrogen atom on the pyrrolidone ring of $\mathrm{PVP}^{47,48}$ and also between the negatively charged $\mathrm{PVP}$ oxygen $\left(\mathrm{N}^{+}=\mathrm{C}-\mathrm{O}-\right)$ and the electron-poor $\mathrm{C}-1^{\prime}$ of $\mathrm{SDS},{ }^{49,50}$ as shown in Figure $5 \mathrm{~A}$.

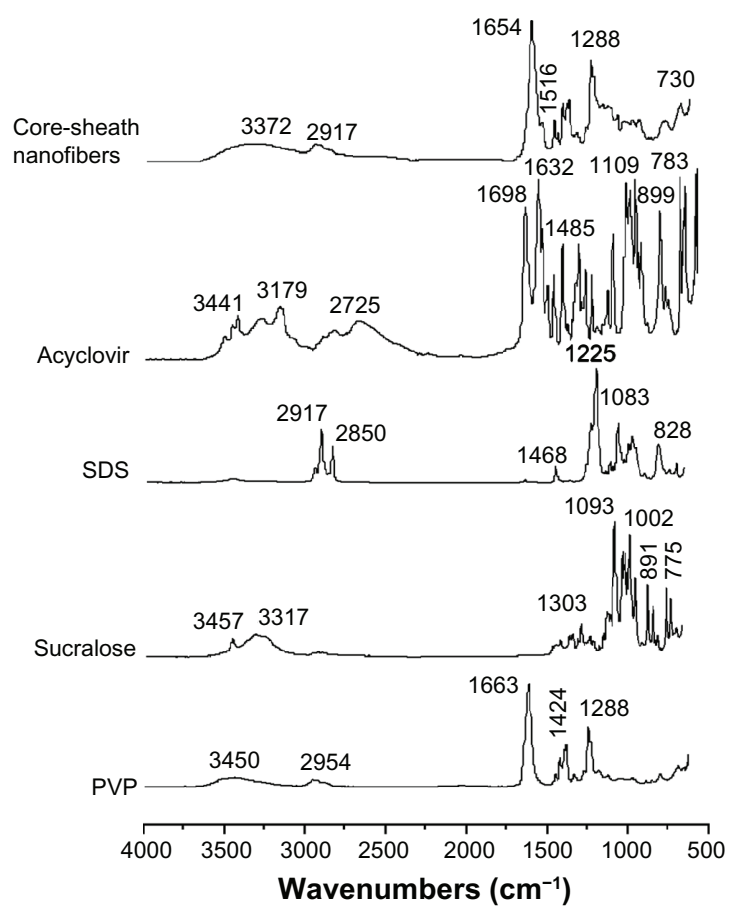

Figure 6 ATR-FTIR spectra of the components (acyclovir, PVP, SDS, and sucralose) and their core-sheath nanofibers at $500-4000 \mathrm{~cm}^{-1}$ and a resolution of $2 \mathrm{~cm}^{-1}$. Abbreviations: PVP, polyvinylpyrrolidone; SDS, sodium dodecyl sulfate; ATRFTIR, attenuated total reflectance Fourier transform infrared. 
Based on the evidence presented, it is postulated that a combination of hydrogen bonding and hydrophobic and electrostatic forces provides an environment that stabilizes the structure, thereby giving a high degree of compatibility between the components that make up the core-sheath nanofibers. This, in turn, creates a homogeneous structure which influences both the stability of the solid dispersion and even distribution of the drug, so facilitating dissolution of acyclovir from the nanofibers.

\section{In vitro dissolution properties}

Acyclovir has an ultraviolet absorbance peak at $252 \mathrm{~nm}$, whereas the other components, ie, PVP, SDS, and sucralose, have no absorbance at this wavelength. Using this parameter, the content of acyclovir was determined by ultraviolet spectroscopy, and samples were calculated from a calibration curve $A=0.05908 C+0.00515(\mathrm{R}=0.9999)$, where $C$ is the concentration of acyclovir $(\mu \mathrm{g} / \mathrm{mL})$ and $A$ is absorbance at $252 \mathrm{~nm}$ (linear range $2-20 \mu \mathrm{g} / \mathrm{mL}$ ).

A comparison of the in vitro dissolution profile for acyclovir from core-sheath nanofibers and that for crude acyclovir particles $(\leq 100 \mu \mathrm{m})$ is shown in Figure 7 . The nanofiber mats released all the encapsulated acyclovir within one minute, whereas only $40.5 \%$ of the drug was released from acyclovir particles left in the dissolution media for one hour.

Methods for improving drug solubility and dissolution rate continue to be sought. ${ }^{51,52}$ Generally, these protocols have been guided by the Noyes-Whitney equation, ${ }^{53,54}$ which defines the dissolution rate $(d X / d t)$ as follows:

$$
d X / d t=(A \times D / \delta) \times\left(C_{0}-X / V\right)
$$

where $X$ is the amount of drug in solution, $t$ is time, $A$ is the effective surface area, $D$ is the diffusion coefficient of the

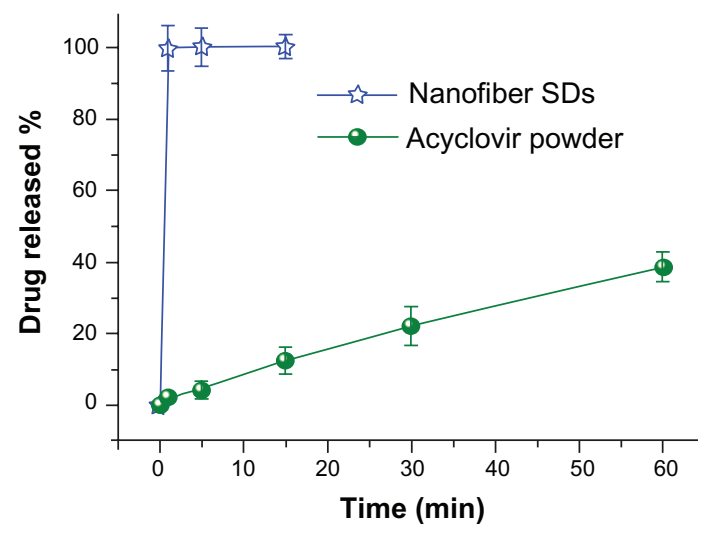

Figure 7 In vitro dissolution profiles of the acyclovir powders and core-sheath nanofiber solid dispersions. drug, $\delta$ is the effective diffusion boundary layer, $C_{0}$ is the saturation solubility of the drug, and $V$ is the volume of the dissolution medium. Based on this equation, the rate of dissolution is directly proportional to the surface area of the drug and to the drug concentration gradients in the dissolution medium, but is inversely proportional to the diffusion layer thickness at the solid-liquid interface.

Core-sheath nanofibers have essential properties for improving the dissolution rates of poorly water-soluble drugs: the nanofibers have a small diameter and a high surface to volume ratio, which means that there is a large surface area for the drug to be in contact with the dissolution media; the nanofiber assembly has a three-dimensional continuous web structure which provides great porosity to facilitate fast mass transformation of solvent and drug molecules from or into the bulk dissolution media; the nanoscale diameter of the nanofibers which greatly decreases the diffusion layer thickness with the uniform PVP-SDS-sucralose/ PVP-acyclovir complex which can improve drug wettability; and the fast dissolution of the core-sheath nanofibers, which could augment local concentrations of supersaturated drug solution, especially in the presence of PVP and SDS, and thus correspondingly increases the drug gradients for rapid diffusion of molecules to the dissolution media. The combined synergistic effect of nanosizing of fibers, the continuous web structure of the nanofibers, and molecular distribution of drug in the filament-forming matrix provide these structures with unique properties for improving the dissolution rate of acyclovir.

\section{In vitro permeation properties}

Comparison of the in vitro permeation profiles for acyclovir from core-sheath nanofibers and crude acyclovir particles is shown in Figure 8. The cumulative permeation percentages

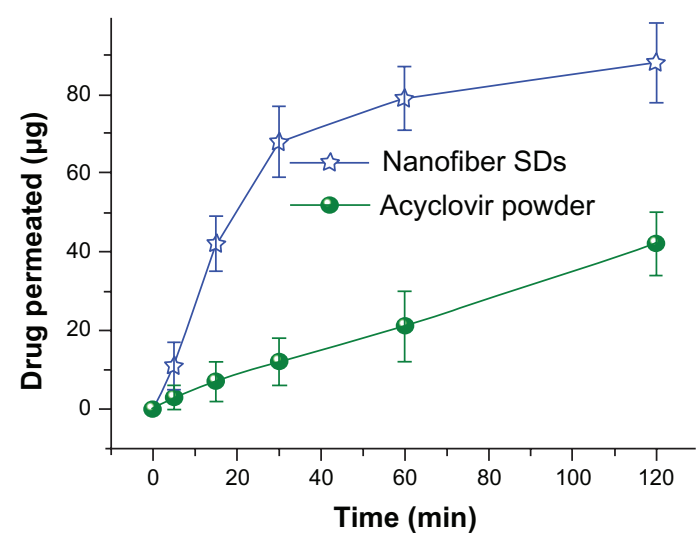

Figure 8 In vitro permeation profiles of the acyclovir powders and core-sheath nanofiber solid dispersions. 
after half an hour for the core-sheath nanofibers and crude acyclovir particles were $68.3 \%$ and $11.4 \%$, respectively. Regression values from the linear release-time equations were estimated for the core-sheath nanofibers and crude acyclovir particles. These were $\mathrm{Q}=2.3095 \mathrm{t}+1.3809(\mathrm{R}=0.9915$, $\mathrm{t} \leq 30$ minutes $)$ and $\mathrm{Q}=0.3408 \mathrm{t}+1.1024(\mathrm{R}=0.99089$, $\mathrm{t} \leq 120$ minutes), respectively, where $\mathrm{Q}$ is total permeation of acyclovir in $\mu \mathrm{g}$ and $\mathrm{t}$ is time in minutes. Thus, the core-sheath nanofibers and crude acyclovir particles had a permeation rate of 0.89 and $0.13 \mu \mathrm{g} / \mathrm{min} / \mathrm{cm}$, respectively.

The core-sheath nanofibers yielded a permeation rate of acyclovir that was over six-fold faster than that of the crude particles. The faster permeation rates from the coresheath nanofibers can be explained in terms of permeability across the sublingual mucosa being a passive diffusion process, and hence faster dissolution of acyclovir would lead to an increased concentration gradient of drug at the mucosal surface. This would facilitate rapid partitioning of drug into the sublingual mucosa and subsequent permeation. ${ }^{55}$ The SDS released from the nanofibers may also improve permeation by extracting intercellular lipids that act as a rate-limiting barrier to the transport of acyclovir molecules. ${ }^{56}$

In addition to the advantages of improved solubility behavior and permeation properties of acyclovir, core-sheath solid dispersions can be post-processed more easily because they have good drug stability due to the steric constraints provided by the small diameter of the nanofibers and the "nanocoating" effect of the sheath on the core drug-loaded region. This would effectively avoid recrystallization and possible growth of a crystal lattice.

Within this context, sucralose, an artificial sweetener, has recently gained popularity because it is 600 times more effective by weight compared with sucrose and does not have the bitter aftertaste characteristic of many non-nutritive sweeteners. The US Food and Drug Administration has approved sucralose, and it is now applied as a general purpose sweetener in foods, beverages, dietary supplements, and medical foods. ${ }^{57,58}$ The positioning of sucralose in the sheath component would effectively provide an acceptable taste for patients if solid dispersions are developed further as oral drug delivery systems. On the other hand, researchers are now focusing on the mass preparation of nanofibers for scaling up, ${ }^{59,60}$ so the development of core-sheath solid dispersions as demonstrated here may offer a solution for development of commercial products that involve poorly water-soluble active ingredients.

\section{Conclusion}

This study has demonstrated that it is possible to prepare a solid dispersion in the form of core-sheath nanofibers using a coaxial electrospinning process for poorly water-soluble drugs. Different functional ingredients can be placed in various locations in the core-sheath nanofibers and provide unique and specific properties for the nanofiber system. The core-sheath nanofibers had an average diameter of $410 \pm 94 \mathrm{~nm}$ with a uniform structure and smooth surface, as demonstrated by FESEM and transmission electron microscopy. X-ray diffraction and DSC results demonstrated that the acyclovir, solid dispersions, and sucralose were distributed in the core/sheath PVP matrix in an amorphous manner. The ATR-FTIR spectra verified second-order interactions suggesting that hydrogen bonding, electrostatic interactions, and hydrophobic interactions occurred among the components, and that these noncovalent forces are likely to play a significant role in promoting the homogeneity of the structure. In vitro dissolution and permeation tests showed that the core-sheath nanofiber solid dispersions could rapidly release all their acyclovir within one minute, with a six-fold greater permeation rate across the sublingual mucosa compared with crude acyclovir particles. The study also provides an example of the systematic design, preparation, characterization, and application of a novel type of solid dispersion consisting of multiple components and with unique structure characteristics. This nanofiber structure has the potential to enhance the dissolution and permeation performance of a series of poorly water-soluble drugs, and could be developed further as a novel oral drug delivery system.

\section{Acknowledgments}

This work was supported by the scientific starting funds for young teachers at the University of Shanghai for Science and Technology (10-00-310-001) and grant 10JC1411700 from the Science and Technology Commission of Shanghai Municipality.

\section{Disclosure}

The authors report no conflicts of interest in this work.

\section{References}

1. Webster TJ. Nanomedicine: what's in a definition? Int J Nanomedicine. 2006;1:115-116.

2. Farokhzad OC. Nanotechnology for drug delivery: the perfect partnership. Expert Opin Drug Deliv. 2008;5:927-929.

3. Allen TM, Cullis PR. Drug delivery systems: Entering the mainstream. Science. 2004;303:1818-1822.

4. Seil JT, Webster TJ. Spray deposition of live cells throughout the electrospinning process produces nanofibrous three-dimensional tissue scaffolds. Int J Nanomedicine. 2011;6:1095-1099. 
5. Jannesari M, Varshosaz J, Morshed M, Zamani M. Composite poly(vinyl alcohol)/poly(vinyl acetate) electrospun nanofibrous mats as a novel wound dressing matrix for controlled release of drugs. Int $J$ Nanomedicine. 2011;6:993-1003.

6. Neves NM, Campos R, Pedro A, Cunha J, Macedo F, Reis RL. Patterning of polymer nanofi ber meshes by electrospinning for biomedical applications. Int J Nanomedicine. 2007;2:433-448.

7. Wang Y, Zhang C, Zhang Q, Li P. Composite electrospun nanomembranes of fish scale collagen peptides/chito-oligosaccharides: antibacterial properties and potential for wound dressing. Int $J$ Nanomedicine. 2011;6:667-676.

8. Teo WE, Ramakrishna S. A review on electrospinning design and nanofibre assemblies. Nanotechnology. 2006;17:89-106.

9. Tran PHL, Tran TTD, Park JB, Lee BJ. Controlled release systems containing solid dispersions: strategies and mechanisms. Pharm Res. 2011;28:2353-2378.

10. Junghanns JU, Müller RH. Nanocrystal technology, drug delivery and clinical applications. Int J Nanomedicine. 2008;3:295-309.

11. Song S, Chen Y, Yan Z, Fenniri H, Webster TJ. Self-assembled rosette nanotubes for incorporating hydrophobic drugs in physiological environments. Int J Nanomedicine. 2011;6:101-107.

12. Chokshi RJ, Zia H, Sandhu HK, Shah NH, Malick WA. Improving the dissolution rate of poorly water-soluble drug by solid dispersion and solid solution-pros and cons. Drug Deliv. 2007;14:33-45.

13. Bikiaris DN. Solid dispersions, Part I: recent evolutions and future opportunities in manufacturing methods for dissolution rate enhancement of poorly water-soluble drugs. Expert Opin Drug Deliv. 2011;8: 1501-1519.

14. Nagy ZK, Balogh A, Vajna B, et al. Comparison of electrospun and extruded Soluplus ${ }^{\circledR}$-based solid dosage forms of improved dissolution. J Pharm Sci. August 23, 2011. [Epub ahead of print.]

15. Vasconcelos T, Sarmento B, Costa P. Solid dispersions as strategy to improve oral bioavailability of poor water soluble drugs. Drug Discov Today. 2007;12:1068-1075.

16. Yu DG, Gao LD, White K, Brandford-White C, Lu WY, Zhu LM. Multicomponent amorphous nanofibers electrospun from hot aqueous solutions of a poorly soluble drug. Pharm Res. 2010;27: 2466-2477.

17. Yu DG, Yang JM, Branford-White C, Lu P, Zhang L, Zhu LM. Third generation solid dispersions of ferulic acid in electrospun composite nanofibers. Int J Pharm. 2010;400:158-164.

18. Yu DG, Shen XX, Brandford-White C, White K, Zhu LM, Bligh SWA Oral fast-dissolving drug delivery membranes prepared from electrospun polyvinylpyrrolidone ultrafine fibers. Nanotechnology. 2009;20: 055104.

19. Yu DG, Branford-White C, White K, Li XL, Zhu LM. Dissolution improvement of electrospun nanofiber-based solid dispersions for acetaminophen. AAPS Pharm Sci Tech. 2010;11:809-817.

20. Yu DG, Branford-White C, Shen XX, Zhang XF, Zhu LM. Solid dispersions of ketoprofen in drug-loaded electrospun nanofibers. J Dispersion Sci Tech. 2010;31:902-908.

21. Chen H, Wang N, Di J, Zhao Y, Song Y, Jiang L. Nanowire-inmicrotube structured core/shell fibers via multifluidic coaxial electrospinning, Langmuir. 2010;26:11291-11296.

22. Wang M, Revil A. Electrochemical charge of silica surfaces at high ionic strength in narrow channels. J Colloid Interface Sci. 2010;343: 381-386.

23. Wang M, Xu L, Li C, Yue Z, Zhai M, Li J. Antipolyelectrolyte swelling of amphiphilic hydroxypropyl methylcellulose phthalate gels. Colloid Surf A Physicochem Eng Asp. 2010;356:89-96.

24. Nirmala R, Kalpana D, Jeong JW, et al. Multifunctional baicalein blended poly(vinyl alcohol) composite nanofibers via electrospinning. Colloid Surf A Physicochem Eng Asp. 2011;384: 605-611.

25. Chen H, Di J, Wang N, et al. Fabrication of hierarchically porous inorganic nanofibers by a general microemulsion electrospinning approach. Small. 2011;7:1779-1783.
26. Dzenis Y. Spinning continuous fibers for nanotechnology. Science. 2004;304:1917-1919.

27. Locertales IG, Barrero A, Guerrero I, Cortijo R, Marquez M, Ganan-Calvo AM. Micro/nano encapsulation via electrified coaxial liquid jets. Science. 2002;295:1695-1698.

28. Xin Y, Huang Z, Li W, Jiang Z, Tong Y, Wang C. Core-sheath functional polymer nanofibers prepared by co-electrospinning. Eur Polym J. 2008;44:1040-1045.

29. Zhang JF, Yang DZ, Xu F, Zhang ZP, Yin RX, Nie J. Electrospun core-shell structure nanofibers from homogeneous solution of poly(ethyleneoxide)/chitosan. Macromolecules. 2009;42:5278-5284.

30. Park CH, Lee J. One-step immobilization of protein-encapsulated core/shell particles onto nanofibers. Macromol Mater Eng. 2010;295: 544-550.

31. Sill TJ, Von Recum HA. Electrospinning: applications in drug delivery and tissue engineering. Biomaterials. 2008;29:1989-2006.

32. Moghe K, Gupta BS. Co-axial electrospinning for nanofiber structures: preparation and applications. Polym Rev. 2008;48:353-377.

33. Dror Y, Salalha W, Avrahami R, et al. One-step production of polymeric microtubes by co-electrospinning. Small. 2007;3:1064-1073.

34. Yu DG, Lu P, Branford-White C, Yang JH, Wang X. Polyacrylonitrile nanofibers prepared using co-axial electrospinning with $\mathrm{LiCl}$ solution as sheath fluid. Nanotechnology. 2011;22:435301.

35. Yu DG, White K, Yang JH, Wang X, Qian W, Li Y. PVP nanofibers prepared using co-axial electrospinning with salt solution as sheath fluid. Mater Lett. 2012;67:78-80.

36. Yu DG, Branford-White C, Bligh SWA, White K, Chatterton NP, Zhu LM. Improving polymer nanofiber quality using a modified coaxial electrospinning process. Macromol Rapid Commun. 2011;32: 744-750.

37. Yu DG, Zhu LM, Branford-White C, Bligh SWA, White K. Coaxial electrospinning with organic solvent for controlling the self-assembled nanoparticle size. Chem Commun. 2011;47:1216-1218.

38. Yu DG, Branford-White C, Chatterton NP, et al. Electrospinning of concentrated polymer solutions. Macromolecules. 2010;43: 10743-10746.

39. Yu DG, Branford-White C, White K, et al. A modified coaxial electrospinning for preparing fibers from a high concentration polymer solution. eXPRESS Polym Lett. 2011;5:732-741.

40. Yu JH, Fridrikh SV, Rutledge GC. Production of submicrometer diameter fibers by two-fluid electrospinning. Adv Mater. 2004;16: $1562-1566$.

41. Díaz JE, Barrero A, Márquez M, Loscertales IG. Controlled encapsulation of hydrophobic liquids in hydrophilic polymer nanofibers by co-electrospinning. Adv Funct Mater. 2006;16:2110-2116.

42. Huang ZM, He CL, Yang A, et al. Encapsulating drugs in biodegradable ultrafine fibers through co-axial electrospinning. J Biomed Mater Res A. 2006;77A:169-179.

43. Yeo LY, Friend JR. Electrospinning carbon nanotube polymer composite nanofibers. J Exp Nanosci. 2006;2:177-209.

44. Sethia S, Squillante E. Solid dispersion of carbamazepine in PVP K30 by conventional solvent evaporation and supercritical methods. Int $J$ Pharm. 2004;272:1-10.

45. Mauro Banchero LM, Ada Ferri DS, Ronchetti S, Sicardi S. Impregnation of PVP microparticles with ketoprofen in the presence of supercritical $\mathrm{CO}_{2}$. J Supercrit Fluids. 2007;42:378-384.

46. Yu DG, Branford-White C, Li L, Wu XM, Zhu LM. The compatibility of acyclovir with polyacrylonitrile in the electrospun drug-loaded nanofibers. J Appl Polym Sci. 2010;117:1509-1515.

47. Pongpeerapat A, Higashi K, Tozuka Y, Moribe K, Yamamoto K. Molecular interaction among probucol/PVP/SDS multicomponent system investigated by solid-state NMR. Pharm Res. 2006;23: 2566-2574

48. Li F, Li GZ, Xu GY, Wang HQ, Wang M. Studies on the interactions between anionic surfactants and polyvinylpyrrolidone: Surface tension measurement, ${ }^{13} \mathrm{C}$ NMR and ESR. Colloid Polym Sci. 1998;276: $1-10$. 
49. Roscigno P, Asaro F, Pellizer G, Ortana O, Paduano L. Complex formation between PVP and sodium decyl sulfate. Langmuir. 2003;19: 9638-9644.

50. Ghebremeskel AN, Vemavarapu C, Lodaya M. Use of surfactants as plasticizers in preparing solid dispersions of poorly soluble API: selection of polymer-surfactant combinations using solubility parameters and testing the processability. Int J Pharm. 2007;328:119-129.

51. Noyes AA, Whitney WR. The rate of solution of solid substances in their own solutions. JAm Chem Soc. 1897;19:930-934.

52. Merisko-Liversidge E, Liversidge GG, Cooper ER. Nanosizing: A formulation approach for poorly-water-soluble compounds. Eur $J$ Pharm Sci. 2003;18:113-120.

53. Wurster DE, Taylor PW. Dissolution rates. J Pharm Sci. 1965;54: 169-175.

54. Verreck G, Chun I, Peeters J, Rosenblatt J, Brewster ME. Preparation and characterization of nanofibers containing amorphous drug dispersion generated by electrostatic spinning. Pharm Res. 2003;20:810-817.
55. Chett DJ, Chen LH, Chien YW. Characterization of captopril sublingual permeation of preferred routes and mechanisms. J Pharm Sci. 2001;90:1868-1877.

56. Nicolazzo JA, Reed BL, Finnin BC. Buccal penetration enhancers How do they really work? J Control Release. 2005;105:1-15.

57. Mead RN, Morgan JB, Avery JGB, et al. Occurrence of the artificial sweetener sucralose in coastal and marine waters of the United States. Mar Chem. 2009;116:13-17.

58. Grotz VL, Munro IC. An overview of the safety of sucralose regulatory. Toxicol Pharmacol. 2009;55:1-5.

59. Lu B, Wang Y, Liu Y, et al. Superhigh-throughput needleless electrospinning using a rotary cone as spinneret. Small. 2010;6: 1612-1616.

60. Varabhas JS, Chase GG, Reneker DH. Electrospun nanofibers from a porous hollow tube. Polymer. 2008;49:4226-4229.
International Journal of Nanomedicine

\section{Publish your work in this journal}

The International Journal of Nanomedicine is an international, peerreviewed journal focusing on the application of nanotechnology in diagnostics, therapeutics, and drug delivery systems throughout the biomedical field. This journal is indexed on PubMed Central, MedLine, CAS, SciSearch ${ }^{\circledR}$, Current Contents ${ }^{\circledR} /$ Clinical Medicine,

\section{Dovepress}

Journal Citation Reports/Science Edition, EMBase, Scopus and the Elsevier Bibliographic databases. The manuscript management system is completely online and includes a very quick and fair peer-review system, which is all easy to use. Visit http://www.dovepress.com/ testimonials.php to read real quotes from published authors. 